\title{
Authors response to Assoc. Prof. Metin Uzun's letter to the editor regarding our study: 'Augmented compression in exchange nailing for femoral and tibia non-unions accelerates time to radiographic union'
}

\author{
Simon B. C. Weil ${ }^{1}$ (D ) Andreas Fontalis ${ }^{1} \cdot$ Myriam Guessoum $^{1} \cdot$ Alex $^{\text {Trompeter }}{ }^{1,2}$
}

Received: 16 August 2021 / Accepted: 27 August 2021 / Published online: 9 September 2021

(c) The Author(s), under exclusive licence to Springer-Verlag France SAS, part of Springer Nature 2021

\section{Dear Editor,}

We would like to thank Assoc. Prof. Metin Uzun for his letter to the editor regarding our study entitled 'Augmented compression in exchange nailing for femoral and tibia nonunions accelerates time to radiographic union' [1].

We note that the mean age between the two groups was found to be statistically significantly different as per table 1 in our study. The noted difference between the ages was not intentional and likely due to the small sample size and retrospective nature of the study. The study was a retrospective analysis of a single surgeon series, and there was always the risk that this would introduce a confounding variable. We had detailed the difference in age in the study, and this was identified as a limitation. However, we also would like to reiterate that the two groups were matched from a mechanical and intervention point of view-only direct exchanges without changes in alignment or alternative fixation strategies were included. Furthermore, age is not specifically an independent factor for poorer bone healing, at least not until the extremes of age [2]. The mean ages of the two groups would not be considered to be at the extreme of age.

This study was intended as a proof of concept, and a large prospective study with the ability to control for confounding variables would be required to support the hypothesis and preliminary findings.

Again we thank the reader for his comments, and hopefully, this response clarifies some of his concerns.

Simon B. C. Weil

Simon.Weil@doctors.org.uk

1 Trauma and Orthopaedics Department, St George's Hospital, Blackshaw Road, Tooting, London SW17 0QT, UK

2 St George's University of London, London, UK
Yours sincerely,

The Authors.

Funding No funding was received for this work.

Availability of data and material Data transparency. Not applicable.

Code availability Software application or custom code. Not applicable.

\section{Declarations}

Conflict of interest The senior author on this paper (Mr Alex Trompeter) has to declare Paid services for Stryker (education and R+D) and Smith and Nephew and Orthofix (Education). No COI relating to this work. No payments for this work. All other authors have no conflicts of interest to declare.

Ethics approval Include appropriate approvals or waivers.

Consent to participate Not applicable.

Consent for publication Not applicable.

\section{References}

1. Weil S, Fontalis A, Guessoum M, Trompeter A (2021) Augmented compression in exchange nailing for femoral and tibial non-unions accelerates time to radiographic union. Eur J Orthop Surg Traumatol 31(5):931-936. https://doi.org/10.1007/s00590-021-02900-w

2. Tanner $\mathrm{M}$ et al (2019) Does age influence the outcome of lower limb non-union treatment? A matched pair analysis. J Clin Med. https://doi.org/10.3390/jcm8091276

Publisher's Note Springer Nature remains neutral with regard to jurisdictional claims in published maps and institutional affiliations. 